\title{
Return Migration after Natural Disasters
}

\author{
Mikiyasu Nakayama (Corresponding author) \\ Graduate School of Frontier Sciences, The University of Tokyo \\ 5-1-5 Kashiwano-ha, Kashiwa, Chiba 277-8563, Japan \\ Tel: 81-4-7136-4869 Fax: 81-4-7136-4842Ｅ-mail: nakayama@k.u-tokyo.ac.jp
}

\begin{abstract}
Nicholas S. Bryner
Emmett Institute on Climate Change and the Environment

University of California, Los Angeles School of Law

385 Charles E. Young Drive East, Los Angeles, CA 90095, United States

Tel: 1-310-794-5132Ｅ-mail: bryner@law.ucla.edu

Satoru Mimura

Global Environment Department, Japan International Cooperation Agency

Nibancho Center Building 5-25, Niban-cho, Chiyoda-ku, Tokyo 102-8012, Japan

Tel: 81-3-5226-9548Ｆax: 81-3-5226-6343Ｅ-mail: Mimura.Satoru@jica.go.jp
\end{abstract}

Received: February 10, 2017 Accepted: February 14, 2017 Published: February 28, 2017

doi:10.5296/jad.v3i1.10742ＵRL: http://dx.doi.org/10.5296/jad.v3i1.10742

\begin{abstract}
This special issue features policy priorities, public perceptions, and policy options for addressing post-disaster return migration in the United States, Japan, and a couple of Asian countries. It includes a series of case studies in these countries, which are based on a sustained dialogue among scholars and policymakers about whether and how to incentivize the return of displaced persons, considering social, economic, and environmental concerns. The research team, composed of researchers from Indonesia, Japan, Sri Lanka, and the United States, undertook a collaborative and interdisciplinary research process to improve understanding about how to respond to the needs of those displaced by natural disasters and to develop policy approaches for addressing post-disaster return. The research focused on the
\end{abstract}




\section{Macrothink}

Journal of Asian Development

ISSN 2377-9594 2017, Vol. 3, No. 1

following three key issues: objectives of return migration (whether to return, in what configuration, etc.), priorities and perceptions that influence evacuees' decision-making regarding return, and policies and practices that are used to pursue return objectives. This special issue includes ten articles on the following disaster cases: the Great East Japan Earthquake in 2011, Hurricane Katrina in 2005 and Hurricane Sandy in 2012, the Great Indian Ocean Tsunami in 2004, and the Great Sumatra Island Earthquake in 2009. Important lessons for the future were secured out of these case studies, covering the entire phase of return, namely planning, implementation, and monitoring.

Keywords: displaced, earthquake, hurricane, livelihood, migration, natural disaster, return, tsunami 


\section{Introduction}

From Hurricane Katrina's devastation of New Orleans and the Gulf Coast to the Great East Japan Earthquake of 2011 and the ensuing tsunami and nuclear reactor meltdown, governments in the United States and Japan have had to engage in massive restoration and cleanup efforts to address significant loss of life, tremendous economic damage, and displacement of entire communities. It was also the case in such countries as Indonesia and Sri Lanka with the Great Indian Ocean Tsunami in 2004 and the Great Sumatra Island Earthquake in 2009.

Disasters often provoke immediate responses and aid. For displaced populations, however, the disruptive effects may continue for years as they struggle to return to affected areas. In Japan, decision-makers and scholars have noted that many evacuees are not returning to their homes following the Great East Japan Earthquake, and that those who have returned face tremendous challenges. In the United States, the return of evacuees to New Orleans and surrounding areas devastated by Hurricane Katrina has been uneven (and often inequitable). In Indonesia and Sri Lanka, the Great Indian Ocean Tsunami in 2004 and the Great Sumatra Island Earthquake in 2009 created a great number of refugees, and some of them have not come back home for various reasons.

Increasingly, questions are being raised about whether damaged areas should be rebuilt in the same way, whether they should be rebuilt differently, or whether people from vulnerable areas should not return to their previous areas of residence at all. Even when policymakers decide to encourage return, persons displaced by a disaster may decide not to return. Conversely, even if policymakers decide to discourage return, displaced persons may fervently seek to return.

Various social, economic, cultural, and environmental factors influence how evacuees consider whether, when, and how to return. Those with strong cultural ties, a sense of place, or social capital are more likely to move back after a disaster. Other factors include job opportunities, home ownership and other wealth, insurance, the quality of education and other social services, engagement in political processes, and the likelihood of a repeated disaster and displacement. Policies at national and local levels may influence decisions by providing compensation for evacuees or other incentives, whereas formation of new ties in resettled areas, economic considerations, or fear and safety concerns may discourage return. Other decisions must be made when safety, environmental, or health concerns make return impossible.

Given the social, economic, and environmental risk that often accompanies post-disaster return, depending on the situation and context, countries and municipalities may wish to be prepared with policy plans and options for whether and how to incentivize return. These strategies should account for longer-term adaptation needs as well as social attitudes.

This special issue features policy priorities, public perceptions, and policy options for addressing post-disaster return migration in the United States, Japan, and a couple of Asian countries. It includes a series of case studies in these countries, which are based on a 
sustained dialogue among scholars and policymakers about whether and how to incentivize the return of displaced persons, considering social, economic, and environmental concerns.

The research team, composed of researchers from Indonesia, Japan, Sri Lanka, and the United States, undertook a collaborative and interdisciplinary research process to improve understanding about how to respond to the needs of those displaced by natural disasters and to develop policy approaches for addressing post-disaster return. This research process included case studies on experiences and policies related to return that were employed following recent disasters, and on attitudes and other factors that influenced how people displaced by these natural disasters responded to the return policies.

The research focused on three key issues:

- Objectives of return migration (whether to return, in what configuration, etc.)

- Priorities and perceptions that influence evacuees' decision-making regarding return

- Policies and practices that are used to pursue return objectives

\section{Findings out of Case Studies}

This special issue includes eleven articles in total, ten articles on the following disaster cases, in addition to this article as an overview of the case studies:

- $\quad$ Great East Japan Earthquake in 2011: five articles

- Hurricane Katrina in 2005 and Hurricane Sandy in 2012: one article

- Great Indian Ocean Tsunami in 2004: two articles

- Great Sumatra Island Earthquake in 2009: one article

Findings out of these case studies are as follows.

Sato (2017) worked on the issue of planning for return of evacuees. He and his associates carried out interviews with the Tomioka town residents in Fukushima Prefecture, who were forced to evacuate from their home town due to the accident of the Fukushima Daiichi nuclear reactors. It turned out that (1) problems that evacuees have faced are very complicated; (2) policy makers have failed to comprehend the complexity of evacuees' situation; (3) present policy, therefore, does not work effectively to relieve the affected people; (4) hastily developed regional restoration plans only deteriorated the affected people's problems; (5) the existing legal instrument for local autonomy did not work effectively to solve the problem; and (6) public opinion made the problems worse. The disparity between the premise of the current reconstruction policies and the evacuees' problems is among the major obstacles. The prevailing situation might lead to the collapse of the present policy and concerned municipalities. Therefore, the following initiatives are required for improvement: survival and continuation of the affected communities, inputs from the communities to the decision-makers by way of the local governments, and long-term policies that take account of the changing livelihood and opinion of the evacuees. 


\section{MInstitute ${ }^{\text {Macrothink }}$}

Bruch et al. (2017) addressed the issue of how the evacuees living in temporary housing regard their livelihood and their return home. They conducted a series of structured interviews with people from Hirono Town, who were still living in temporary housing four and a half years after the disaster, to understand why people were still in temporary housing, rather than moving back to Hirono Town or on to more permanent arrangements in other locations. Five key factors were identified as to why people stayed in the temporary housing: (1) a new sense of community in the temporary housing; (2) convenience of shopping, medical care, and dental care, as well as (to a lesser degree) education and recreational opportunities; (3) a sense of injustice and inequality in the benefits they were receiving; (4) concerns about radioactive contamination; and (5) a desire to receive compensation. The people in temporary housing all had their own reasons for staying. Some reasons were negative, such as a sense of injustice, fear of radioactive contamination, and a desire for compensation. Other reasons, though, were positive. They had constructed new lives in the temporary housing, had built a new social support network, and had a situation with greater convenience. Many people had both positive reasons for staying and negative reasons for not leaving temporary housing. Through the more than two years during which the foreign researchers visited the temporary housing units with residents of Hirono Town, they saw the town authorities take many measures that address their preliminary and advanced research findings.

Takagi (2017) aimed at clarifying the evacuation behaviors of the residents in a small rural community in Iwaki City, Fukushima Prefecture at the Great East Japan Earthquake on March 11, 2011 and described how their personal relationships changed subsequently. This district suffered more impact from the nuclear disaster caused by the Tokyo Electrical Power Company's Fukushima Daiichi Nuclear Power Station accident than from the earthquake itself. A split in the community emerged after the earthquake, which arose from the residents' various evacuation behaviors and disagreement in their attitudes toward radioactivity. For example, a serious conflict occurred between those who returned from out-of-district evacuation ("escapees") and those who consistently stayed within the district ("non-escapees"). However, on the other hand, to maintain their community functions, there was an attempt made by the returnees inside the community to temper the conflict and another attempt provided from outside of the community, such as the re-start of university student experience program, which had been carried out by the residents before the earthquake. Now that nearly six years have passed since the earthquake, the community conflict is becoming less obvious, but is not yet completely solved.

Chosokabe, Sakamoto, and Nakayama (2017) touched upon the issue of sharing of information and ideas among stakeholders involved in the planning and implementation of the evacuees' return. They examined the case of the public's participation in the reconstruction of the areas in the Fukushima Prefecture of Japan affected by the disaster of the Great East Japan Earthquake in March 2011. The study aimed at (i) identifying the topics discussed and shared among the residents, and (ii) revealing the contribution of the mass media to ensure information transparency in the recovery planning process. The correspondence analysis of the text mining was applied to (a) the text data of dialogue among 


\section{MInstitute ${ }^{\text {Macrothink }}$}

the government officials of the disaster affected municipalities and (b) the newspaper articles. The dialogues used as texts for the analysis were from the sessions at the international forum "Thinking from disaster affected areas and Hirono" held at the Hirono town in September 2015. The articles, which appeared between March 11, 2011 and December 31, 2015 in the Asahi Shimbun, a nation-wide newspaper in Japan, were also used for the analysis. The similarities and differences were identified between the topics discussed by the dialogue participants and those that appeared in the newspaper articles. It turned out that some important topics discussed in the dialogues were not adequately addressed in the newspaper articles. This implies that the coverage by the mass media has a lot of room for improvement, particularly in promoting the transparency of information and administrative agenda among the citizens and the municipalities.

Sasaki (2017) aimed at (a) verifying whether reports by the mass media correctly reflected people's opinions and thoughts concerning the Great East Japan Earthquake and the nuclear power station accident of Fukushima, and (b) confirming the underlying structure of the issue concerning evacuees who are not willing to return, using as a case study the Fukushima evacuees especially focusing on Hirono Town. Text mining analysis was conducted for the news articles that appeared in the Fukushima Minpo, the local newspaper of Fukushima, from November 2015 to October 2016. The number of Japanese characters examined in the study reached nearly 65,000 in total. It turned out that many of the words that had a close relationship with "return" were in accordance with the key elements identified in other surveys concerning the issue of residents' return. The accuracy of media reports has been, in general, confirmed. It should also be noted that the close relationship between "return" and "Nuclear Power Station" was not confirmed. It may presumably imply that the mass media dissociated the Nuclear Power Station from the issue of residents' return, because everybody obviously assumed that the accident of the Nuclear Power Station and subsequent problems were the major obstacles for the residents to return home.

Bryner, Garcia-Lozano, and Bruch (2017) reviewed the literature on factors affecting individual and household choices to return or relocate following Hurricane Katrina in 2005 and Superstorm Sandy in 2012 in the United States. Studies identified five major factors influencing these decisions: the habitability of homes; access to affordable housing; financial burdens, including direct costs as well as shortcomings or delays in government-funded assistance programs; the extent of restoration of public services and facilities; and sense of place and identity. Additional salient factors included fear of future disasters, stress associated with the recovery and rebuilding process, and the loss of employment. Policy responses after Katrina and Sandy reflected a variety of approaches across two dimensions: whether to encourage or discourage return, and whether to compensate for past losses or invest toward building resilience to future disasters. However, the authors observed that policymakers are bound by financial, political, and, in some cases, constitutional limits, in their ability to address challenges with post-disaster return. Decision-makers should maximize the effectiveness of their policies by developing a better understanding of the critical factors that affect household decisions to best align the limited policy options available with underlying goals for long-term sustainability and resilience of disaster-affected communities. 


\section{MInstitute ${ }^{\text {Mech }}$}

Manatunge and Abeysinghe (2017) addressed the lessons learned in Sri Lanka after the Great Indian Ocean Tsunami in 2004 regarding how post-disaster housing projects should be implemented effectively. The authors noted that little research has been conducted to study the levels of satisfaction of affected persons in the long term after receiving houses in new settlements with "better" socio-economic and physical facilities. The post-disaster resettlement schemes established, therefore, provide an ideal setting to study the factors affecting the long-term satisfaction of communities in the context of providing permanent housing. The study focused on twelve such sites in Sri Lanka. The elements/criteria chosen to assess the long-term satisfaction of the resettlers consisted of factors related to site selection, the design of dwelling units and surroundings, material well-being and provision of services and infrastructure, and aspects related to social factors and perceptions regarding the resettlement process, neighborhood, and social interactions. The study suggests that despite the availability of sufficient funding, the opportunities to plan, design, and implement sustainable community-responsive resettlement programs for tsunami affected households were largely missed. The resettled communities are not satisfied due to various physical, environmental, and socio-economic factors, such as inappropriate site selection and design of functional spaces, poor construction of houses and common spaces, and lack of easy and convenient access to social infrastructure assets.

Croshaw (2017) dealt with the after-relocation issue of IDP (internally displaced people) with the case of the population displaced in Maldives by the Great Indian Ocean Tsunami in 2004. The tsunami caused up to one-third of the then total Maldivian population of 393,000 to be displaced. The Maldives had not experienced a major natural disaster before the 2004 tsunami that would necessitate a plan for emergency services and IDPs. The Government thus established the ado-hoc agency of the National Disaster Monitoring Centre (NDMC) to handle the coordination of the relief efforts and all IDP-related services. Identifying the IDPs proved to be very challenging due to the extensive travel to all the islands and the arduous process of distinguishing an IDP from their host families. It took three to four years to register all the IDPs on the islands. The planning process for IDP housing included community consultations and involvement of IDPs, although women were often underrepresented at these meetings. The temporary housing situation faced difficulties as time passed, for host communities felt burdened due to shared housing and other resources, which resulted in some conflicts between IDPs and their host communities. The different island identities sometimes created social conflicts between and within IDP families as well as between IDP families and their hosts. The transition from IDPs to permanent residents also had problems. Very generous assistances to IDPs proved a disincentive to leave the temporary housing. Despite the problems observed, the Government of Maldives took steps to improve the post-disaster response, protect the rights of IDPs, and involve IDPs in the planning process.

Karimi (2017) shows the findings out of the survey on 400 households of return migrants associated with the West Sumatra Large-Scale Earthquake on 30 September 2009. The education level of return migrants is higher than the stayers. More than $88 \%$ are living from trade, public services, and fishing. Above $50 \%$ is living from trading alone. The return 
migrants shared a similar employment status with the stayers. Entrepreneurial status is more important for return migrants than for the stayers. Income distribution shows a different pattern between return migrants and the stayers. The return migrants have a more significant part of the maximum income group. The return migrants at the highest income group account for $27 \%$, which is obviously greater than the stayers.

\section{Conclusions}

As is the case with other ordinary local or regional development programs, a reconstruction program after a disaster, which includes the measures to address the return of evacuees to their homes, may be split into the phases of planning, implementation/construction, and monitoring/follow-up.

With respect to the planning phase, the article by Sato (2017) addressed the relationship between the evacuees in Fukushima and the local as well as the central governments. The survey findings on the local townsmen revealed that the policy makers failed to comprehend the complexity of the problems that the evacuees faced. The study also suggested that the hastily developed regional restoration plans only resulted in a deterioration of the affected people's problems. The disparity between the premise of the current reconstruction policies and the evacuees' problems was identified as the major obstacle. Sato (2017) recommended that the inputs from the communities should be brought to the attention of the decision-makers by way of the local governments, and that the long-term policies should take account of the changing livelihood and opinions of the evacuees.

Also, regarding the planning in post-disaster reconstruction, Manatunge and Abeysinghe (2017) suggested, based on their case studies on the post-disaster resettlement schemes in Sri Lanka, that the authority failed to plan, design, and implement resettlement programs for tsunami affected households in a sustainable manner not because of the lack of funds, but because of their inadequate approach to the situation.. The resettled communities are not satisfied due to various physical, environmental, and socio-economic factors, as stipulated in their articles (Manatunge \& Abeysinghe, 2017). They attributed the failure to (a) lack of planning guidelines, policies, or regulations when the disaster took place, (b) lack of capacity in the central and local government to coordinate the rehabilitation affairs properly, (c) absence of effective command structures and communication channels within the governmental organizations for decision-making, (d) inconsistent application of regulations. The government agencies were under-resourced and thus they were unable to manage the immensely increased workloads. There were notable deficiencies of capacity at governmental agencies, especially at the local level, regardless of their willingness to undertake more work for coordinating and guiding the resettlement process. What is worse, despite the government-enacted planning guidelines for disaster housing reconstruction, only a few donors sought planning approvals before implementation. The under-resourced government agencies, under immense pressure to expedite implementation, allowed the donors to commence the projects without prior approval. The absence of planning documentation, proper implementing guidelines, and the absence of mechanisms for grievance redress caused significant problems for householders. Although the lack of capacity in the governmental 


\section{Ml Macrothink}

agencies is difficult to address under emergency, the behavior of donor agencies seems to have room for improvement. As for the governments in the developed world, Bryner, Garcia-Lozano, and Bruch (2017) urged that decision-makers should maximize the effectiveness of their policies by developing a better understanding of the critical factors that affect household decisions.

We tend to imagine that the life of the evacuees following the Great East Japan Earthquake would be miserable in the temporary housing, for they were ordered to leave their homes suddenly and shortly after their suffering from the earthquake and subsequent tsunami. Bruch et al. (2017), however, found, to our surprise, that more than $70 \%$ of the residents in the temporary housing felt very happy or somewhat happy about their stay. They had both positive reasons for staying and negative reasons for not leaving temporary housing. These evacuees constructed new lives in the temporary housing, built anew their social support network, and had a situation with greater convenience. This implies that they may not be motivated to go back home, unless they have some compelling reasons to do so, provided their livelihood after return would not be as convenient as in the temporary housing. This should be one of the most important lessons to be learned for the sake of reconstruction planning and implementation in their home areas.

The evacuees may have problems not only with the government, but also among themselves after returning home, for they may find that the personal relationships among them have changed drastically. Takagi (2017) worked on the people in Fukushima, who evacuated from their homes due to the explosion of the nuclear reactors after the Great East Japan Earthquake and came back home when the restriction was lifted. They suffered from serious conflicts between those who returned from out-of-district evacuation and those who consistently stayed within the district. Although the observed conflicts have become less visible with time, it should be regarded as one of the most important lessons learned out of the cases in Fukushima.

Two articles in this special issue feature text mining as a numerical analysis methodology to address the issue of evacuees in Fukushima following the Great East Japan Earthquake. Both articles intended to find out if the newspaper articles properly reflected the opinions and minds of the local people, namely local government officials and residents. Chosokabe, Sakamoto, and Nakayama (2017) used text mining as the methodology to identify the topics discussed and shared among the residents and to figure out the contribution of the mass media to information transparency for recovery processes. They used for analysis the text data of dialogue among the participants in the local workshops and the newspaper articles that appeared in a nation-wide newspaper. It turned out that some important topics discussed in the dialogues were not adequately addressed in the newspaper articles. Sasaki (2017) also applied text mining analysis to the news articles that appeared in the Fukushima Minpo, the local newspaper of Fukushima. He found that many of the words that had a close relationship with "return" were closely related with the key elements identified in other surveys. This implies that the media reports properly reflected the minds of the local residents. The observed difference may be that the subjects covered by a nation-wide newspaper are not always consistent with the same by a local newspaper. Exploring the difference in the 
coverage of subjects by nation-wide and local newspapers should be an interesting research agenda for further endeavor.

The experiences accumulated by the Government of Maldives (Croshaw, 2017) vividly illustrate how they dealt with issues which they had never faced before. They somehow managed the difficult situations by securing assistance from the international community. They also established an ad-hoc agency to address the recovery from the disaster. The lessons from this case study should be widely disseminated, so that how a historically unprecedented disaster could be dealt with through orchestration of a national government and the international community.

The differences between returned migrants and stayers found by Karimi (2017) may suggest that host communities may suffer from the stayers in low-income category after return of high-income migrants. How these stayers should be motivated to return is not an easy question and further studies should be carried out with various cases to seek a solution. Sharing of duties to take care of the stayers between disaster-affected area and host community should also be examined.

\section{Acknowledgments}

The studies by the research team were funded by the Mitsui \& Co., Ltd, Environmental Fund, JSPS KAKENHI Grant Number 15H02864 and the Graduate School of Frontier Sciences, the University of Tokyo. Support was also provided by the Reconstruction Agency of the Japanese Government through the Hirono Town Government in the Fukushima Prefecture.

\section{References}

Bruch, C., Karimi, S., Manatunge, J., \& Nakayama, M. (2017). Barriers to long-term return after the Great East Japan Earthquake: Lessons from Hirono Town. Journal of Asian Development, 3(1), 23-39. http://dx.doi.org/10.5296/jad.v3i1.10650

Bryner, N. S., Garcia-Lozano, M., \& Bruch, C. (2017). Washed out: Policy and practical considerations affecting return after Hurricane Katrina and Superstorm Sandy. Journal of Asian Development, 3(1), 73-93. http://dx.doi.org/10.5296/jad.v3i1.10590

Chosokabe, M., Sakamoto, M., \& Nakayama, M. (2017). Dialog analysis using a text mining approach: Case study on Hirono Town. Journal of Asian Development, 3(1), 51-64. http://dx.doi.org/10.5296/jad.v3i1.10583

Croshaw, H. R. (2017). In the wake of the 2004 Great Indian Ocean Tsunami: Internally displaced persons and the natural disaster response in the Maldives. Journal of Asian Development, 3(1), 125-143. http://dx.doi.org/10.5296/jad.v3i1.10755

Karimi, S. (2017). Return Migration After 30 September 2009 Earthquake in West Sumatra, Indonesia. Journal of Asian Development, 3(1), 144-155. http://dx.doi.org/10.5296/jad.v3i1.10714

Manatunge, J., \& Abeysinghe, U. (2017). Factors affecting the satisfaction of post-disaster resettlers in the long term: A case study on the resettlement sites of tsunami-affected 
communities in Sri Lanka. Journal of Asian Development, 3(1), 94-124. http://dx.doi.org/10.5296/jad.v3i1.10604

Sasaki, D. (2017). The basic trend of media reports on residents' return in Fukushima: In the realms of text mining analysis. Journal of Asian Development, 3(1), 65-72. http://dx.doi.org/10.5296/jad.v3i1.10572

Sato, A. (2017). The structure of problems surrounding the Fukushima Nuclear Accident evacuees. Journal of Asian Development, 3(1), 12-22. http://dx.doi.org/10.5296/jad.v3i1.10581

Takagi, T. (2017). Evacuation and community issues caused by nuclear disaster in Fukushima, Japan. Journal of Asian Development, 3(1), 40-50. http://dx.doi.org/10.5296/jad.v3i1.10578

\section{Copyright Disclaimer}

Copyright for this article is retained by the author(s), with first publication rights granted to the journal.

This is an open-access article distributed under the terms and conditions of the Creative Commons Attribution license (http://creativecommons.org/licenses/by/3.0/). 